\title{
THE IMPACT OF DIGITALIZATION TO THE STEEL INDUSTRY A PLANT ENGINEERING POINT OF VIEW *
}

Markus Reifferscheid ${ }^{1}$ Dipl. Ing. Harald Rackel${ }^{2}$

\begin{abstract}
Industry 4.0, Digitalization, Internet of Things (loT) and Cloud Computing are predominant topics in the world economy at the moment. At the ABM week $2017 \mathrm{Dr}$. Markus Reifferscheid, Head of Research \& Development of SMS-group, will talk about the proceeding digitalization in the steel industry with selected examples of SMS-group. He will present advanced concepts and solutions which are currently being developed.
\end{abstract}

Keywords: Digitalization; Industry 4.0; Smart Steel Plant; Intelligent Production; Transformation of Value Chain.

1 Dr. Ing., Senior Vice President Research \& Development-SMS-group. GmbH

2 Dipl. Ing.; Member of the Managing Board at SMS-group GmbH.. 


\section{Introduction}

Digitalization/ Industry 4.0 is a topic that almost everybody is talking about and focusing on. From the steel industry's point of view, the main target is the creation of the "Smart Steel Plant" which allows an intelligent and almost autonomous production of steel. Digitalization is an evolutionary process. Besides technical processes it changes internal working processes in the value chain of steel industry. The question to be answered is: Where can digitalization help to develop:

- Future-oriented steel products

- Economic and flexible manufacturing of steel products

- Lean processes and cost-structures under consideration of environmental and legal standards

It is obvious that reaching these objectives through digitalization will have an impact on almost all processes of steel producers. It will affect the horizontal value chain from the supply until the customer network. At the same time, it will have an influence on the vertical value chain from product development until the sales of products and services.

In the last years, SMS-group developed and implemented various products and processes which are related to Industry 4.0 in the steel industry. And besides the measures that are already successful in place, the development of products, services and concepts is a constant process based on close collaborations with customers.

This paper describes the impacts and opportunities of digitalization on steel producers and their value chain. Furthermore the paper gives an overview of the solutions SMS-group has developed and how they can help customers to reach the goal of evolving into a "Smart Steel Plant".

\section{The challenges}

All of our customers face similar challenges

- keeping steel and its various characteristics as an advanced material competitive on the market

- securing competitive position through lean processes and cost structures while using resources carefully

- continuously achieving the highest product quality while reaching a high output

- maximizing the plant performance while having minimum maintenance costs and low capital employed

- flexible production planning with variable and partly small batch sizes while keeping delivery dates

Parameters change permanently, like the costs for raw materials, energy and personnel as well as legal regulations, for instance environmental and legal standards.

So how needs Industry 4.0 - Digitalization to be regarded in this context? Digitalization is not an end in itself. It is about answering the question: 'At what point can digitalization help to achieve the company goals more sustainably and value generating?' 
For plant operators the focus is on the 'smart steel plant', which enables an intelligent and mainly autonomic steel production. It is characterized by the networking and collaboration of man and machine in dynamic production processes which optimize in real time within the value chain.

\section{What does Industry 4.0 stand for?}

Industry 4.0 stands for an already running process which captures the value chain network. It comprises the vertical value chain (within the company) and the horizontal value chain (supplier to customer) and it is going to fundamentally transform both of them. All participants in the value chain network are affected by it.

The 'Process Industry 4.0', Figure 1, is defined by

- the current trend towards digitalization and a real time, open data exchange and access to all participants (people and machines) in the production processes of the value chain network. This includes the methods Internet of Things (loT) and Internet of People (loP)

- the creation of a digital twin/shadow of the real plant, the process or of the product by combining the actual and target data of the mechanics, the functions and the procedures through sensor technology, automation and software

- the usage of networked sensors and mobile computer capacities in so called embedded systems and their networking with the IT inventory system in a cloud, so relevant information is available, individually reconditioned in real time for man and machine at any place

- the extension of the automation and production control system by introducing data analyzing methods (Big Data Analysis - Artificial Intelligence) towards self-optimization, self-configuration, self-diagnosis, pattern recognition and intelligent, supporting systems for employees at the plants

- the skill of 'cyber-physical systems' (CPS) to make decisions autonomously and to reach an equal collaborative cooperation with the employees. The safety and the need for protection of people, process and machine come first 
Figure 1: Industry 4.0 as a process

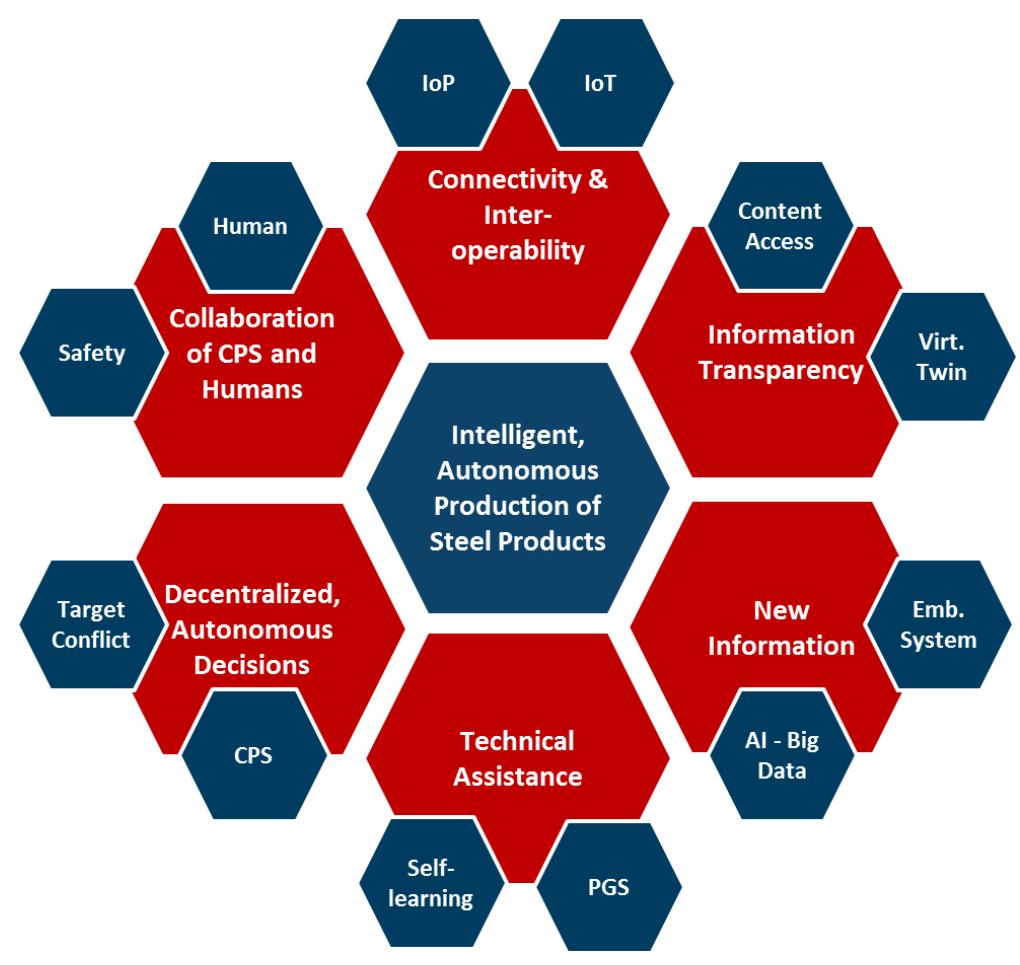

\section{Experiences with digitalization already exist}

When SMS-group began dealing with the topic intensively, it was clear that the topic 'Industry 4.0' had already been in some of our corporate processes in the past without being labeled as such. This is an insight which many of our customers confirm for their production processes.

In the following, there are two application examples that prove this statement. SMSgroup has been dealing with the topic area 'virtual technologies' (virtual reality and augmented reality technologies) and the associated basis technologies like interactive real time visualization, multimodal interaction etc. since 2000.

\section{Digital workshop}

In this context SMS-group has recognized the topic 'multidisciplinary, cooperative collaboration' as a very significant work area and advanced it towards the 'digital workshop'. It forms the working and communication platform for multidisciplinary, cooperative collaboration with trade-spanning tasks. It uses miscellaneous native data or data exchange formats (IGES, JT, WRL) from the 3D-CAD-Systems of the construction departments and enables the coupling of simulation data to movements of plant components and products. Virtual technologies are nowadays used as a tool to secure planning and construction results. The tested field of application includes, among others, Sales with their interactive product presentations, Order Handling with the integration test of the construction department as well as Service for training purposes. The virtual, multidisciplinary securing of the engineering, if necessary under inclusion of the customer in a multi-user environment as a special work environment, allows effective matching procedures and minimizes adjustments later on, meaning they secure order handling time and costs, Figure 2 on the left. 
A current overview of the applied simulation tools and models, as well as a description for the systematic calculation process during the simulation-assisted plant design and dimensioning, can be found in [1].

\section{Plug \& Work - Hardware-in-the-Loop-Simulation environment}

With the increase in computer performance as well as the development in the area of simulation of multi body systems it is possible to simulate complex machines and plants in their kinematic and dynamic performance in real time and to operate on a hardware-in-the-loop-configuration on an actual control. With this, a functional test of the control or the programmed control process is already possible before the commissioning (virtual commissioning). This functional securing of the automation solution takes place during the integration test of the automation. With that manufactures will be put together to a digital product. The simulation test includes genuine automation components (control desks, Programmable Logic Controller, process computers etc.) and the customized control concept. Intersection points get tested and pre-optimized automation parameters get validated. Complex control functions get visualized involving CAD models and can be used for customer training. This strategy ensures short commissioning periods while having a steep upward curve, which means stable production and good product quality from the beginning, Figure 2 on the right.

Figure 2: Industry 4.0-smart plant engineering at SMS-group
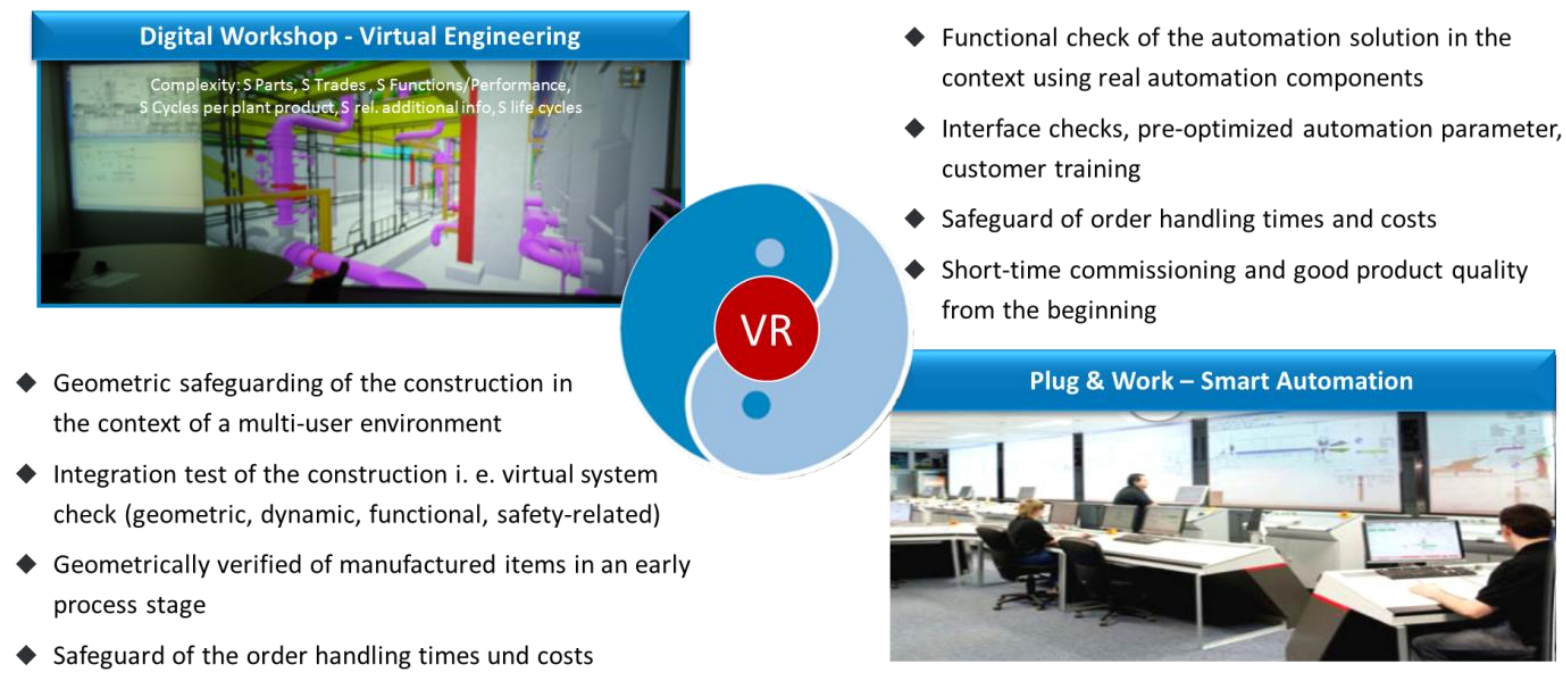

The digital engineering methods are widely used these days and productively applied for the virtual commissioning of entire plants, like described in [2], [3].

So digitalization is not completely new territory neither for plant operators nor for SMS-group. Nowadays SMS-group sees Industry 4.0 as an integral process which creates a different added value. We will have to connect and cooperate with our customers and suppliers even closer to reach an optimal solution.

\section{The most urgent questions and expectations of our customers}

SMS-group handles the topic of digitalization very openly. At first, numerous interviews within the frame of a so-called 'Ideation Lab' were conducted internally, 
with customers and suppliers. The topic raises questions and arouses varied concerns on many sides. The most important topics we identified were:

- How does digitalization influence the business model? How is digitalization supposed to increase process efficiency?

- How do I make sure that knowledge and process information stay secure when opening the Internet of Things? How do I make sure that the production plant does not get vulnerable?

- How do I use digital processes and digital transparency without feeling like I am monitoring everything and everyone? What legal implications come with digitalization?

- How do I avoid dependency? How do I make a lifecycle partnership with a supplier work?

- How does all of this fit into my already existing automation and IT structure? What standards apply here?

- Which new concepts will the present employees have to cope with? How do I get the competencies to be able to answer these questions confidently?

There are also chances and expectations on the topic digitalization. Following examples will be given representative of the involved working area.

- The supply chain management is based on the consistent imaging of the production and material flow and of the order process from the customer order and the production order up to the supplier. Employees rely on digital real time simulation and optimization tools to be able to plan production short-termed so that they can make better predictions on production flow and energy consumption. They expect flexible, cooperative logistics solutions with their suppliers of raw materials, consumables and spare parts. SMS-group has already realized first warehousing concepts for spare parts, meaning SMS takes over the warehousing of spare parts for the customers as a service. Economies of scale on combining spare part portfolios open up cost reduction potential.

- the Sales department demands digital tools for improved pricing, transparent delivery date determination and solutions for 'digital shadows' of products and processes for documentation for the customer.

- The IT and automation provider as well as the IT department in the production plants face the challenge of capturing all data and information from the production (plants, processes, products) consistently across process steps, and if applicable across all locations, and to process and file them in real time in a so called 'Unique Source of Truth'. For this the right information must be available at any time, appropriately rehashed, anywhere and secure for all parties involved (man and machine). This is a big challenge taking into 
account the heterogeneous plant and automation solutions, the many existing 'production islands' from the last two to four decades and the still common processes in hard copy. There is still a lot of basic work to be done in many areas.

- Production especially focuses on the usage of artificial intelligence in big dataanalyses to be able to monitor and operate the processes of self-learning algorithms even better. Today purely physically based model approaches are possibly being extended or even replaced by data-driven models. The trend towards predictive maintenance and service solutions for key components relevant to production will also advance. For plant operators and plant manufacturers it will particularly matter to upgrade the current asset investment with the respective sensor technology and intelligence. The tracking of products and components, regardless of the location, but also of employees for safety purposes will become more important.

Concerning quality management, functional and geometric matching of quality information to the product and the tracking by the entire plant in real time as well as the uninterrupted combining of information to the product relevant for quality along the production process have priority. This enables a broadly automated evaluation of the product quality and a multilevel comparison of the reached product quality with the purchase requisition and a direct response of the results to the production planning. Decisions relevant to quality have to be initiated early in the process to keep the processing depth low should there be deviations or to counteract process deviations on time.

\section{How does SMS-group proceed?}

SMS-group counts on the Design Thinking Approach, typically used by digital startups. The understanding of customer needs or of 'pain points' making interviews or sheer observation is a main focus. After that an agile 'rapid prototyping phase' follows, in which specialists prototypically implement first solution approaches and validate and optimize them with the customer. In this way a so called 'Minimum Viable Product' (MVP) is created, which means a minimum solution which adds value and which is developed in the same manner (test, validate and improve). The term 'sustainability' is permanently focused. It is not about digitalizing whatever works but about implementing only that which brings additional benefit.

There is a change arising for SMS-group as a plant manufacturer, which is that costbased business models will be complemented by value-based business models in the future or will be replaced by them. In other words, the business with plants remains but it will be connected to innovative, digital services in the future. This requires a reliable and confidential handling of information and data which we share with our customers and they share with us.

This shows that digital system solutions bring plant manufacturer and plant operator much closer together and that corporate processes on both sides must be made transparent. 
A further central task that we as SMS-group see in digitalization is the mastering of the Big Data Management, as digital internet companies demonstrate. The task is to evaluate data from production plants and production control system systematically and permanently and to take the basis of decision-making from it, for example in the sense of function optimization. Function optimizations raise reserves and a measurable effect on the customer is often reached in short time. This is a benefit which our customers are quite willing to reimburse.

Taken from a good data basis decisions on lucrative investments and development activities can be made, for instance for assistance systems or extensions of existing automation systems. The data and methods build the basis for new business models around digital services, also outside the industry.

\section{Exemplary solutions}

As a plant manufacturer SMS-group expects that crucial changes within the digitalization will hit the production, maintenance and quality processes first. For this, solutions ready for the market have already been developed and are in use with the plant operators.

\section{Embedded systems}

In the future so called ,embedded systems' will be a fixed part in our components and plants. They document and analyze the behavior of the components in operation and initiate appropriate measures autonomously if necessary. The system in an intelligent spindle in a hot rolling mill of a Chinese customer is exemplary for this. The electronic component with CPU is hardly any bigger than a business card and firmly integrated in the spindle. The energy supply for at least two years is provided by an Energy Harvesting System, which uses the rotation of the spindle as an energy source. The system monitors the spindle regarding characteristic vibrations and torque loads. The embedded system generates data, the evaluation of data and measure initiation, for example inspection and maintenance measures itself. A connection to existing IT or automation solutions is possible but not necessary. With this the solution is ideal for the refitting in an existing plant. The access to the system data over external computer systems for further analysis is possible at any time. Current measured values and evaluated data information can also be displayed on mobile systems, Figure 3. 
Figure 3. Intelligent spindle with an embedded system for condition monitoring

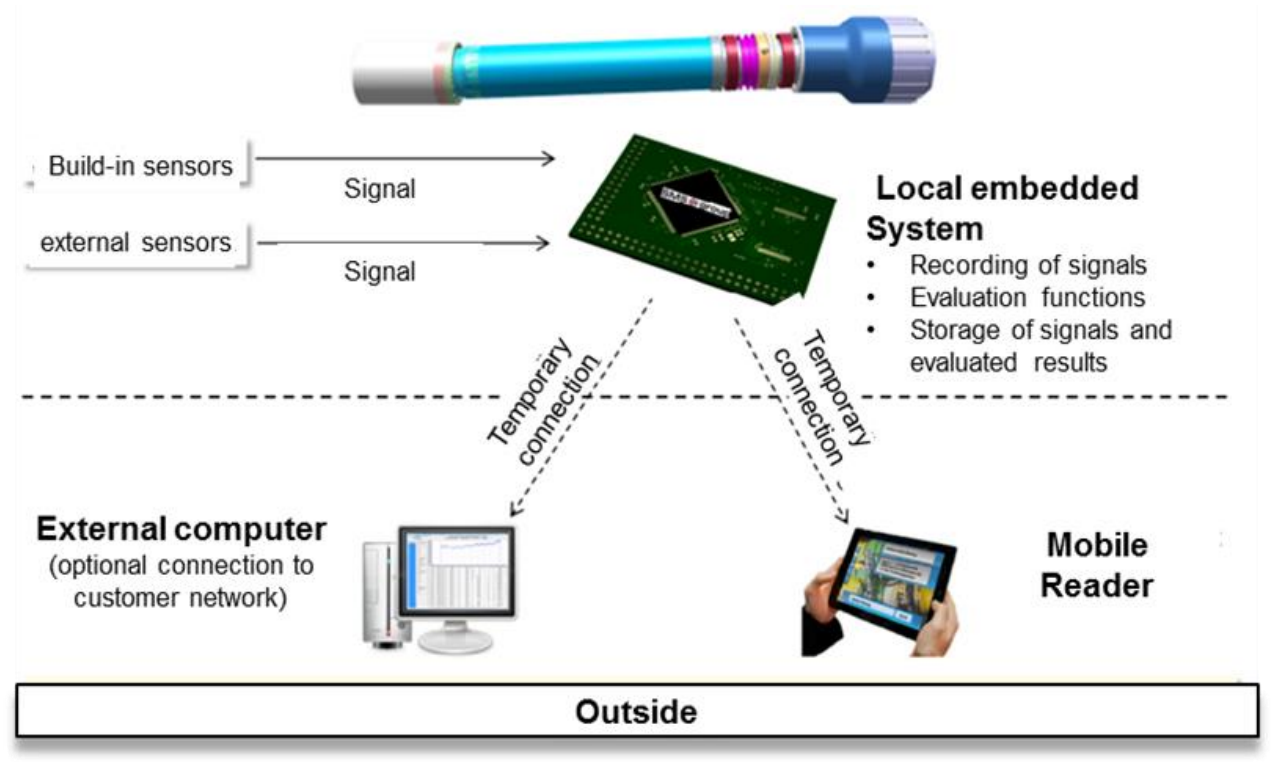

\section{Intelligent ladle management in a steel plant}

The primary goal of the model-based ladle management system is to calculate the temperature of all steel plant ladles to perfectly meet the temperature frame for the casting operation considering the planned process control and the current ladle condition. Besides the modeling of the temperature fields of ladle bodies, refractory lining and steel melt the permanent localization of the ladles in circulation of the steel mill using RFID, Beacon or IR image recognition technologies has priority. For model support measuring data from integrated temperature sensors, infrared cameras as well as information from the ladle delivery or maintenance regarding brickwork and remaining wall thickness are implemented. The product currently has been commissioned at a German customer.

\section{Plant control with virtual support - Augmented Operation}

The solution of the SMS-group subsidiary AMOVA is exemplary for an Augmented Operation for an optimized logistics management in a coil high bay warehouse. For process control, monitoring and optimization a digital twin of the high bay warehouse is used. This twin displays the entire high bay warehouse including its transport systems and processing aggregates as well as the dynamic processes in a 3D surrounding. Information relevant for product and process from the automation system is integrated in real time in the visualization and available on demand. The operator of the high bay warehouse tracks any storage processes in reality and in the virtual surroundings. He can also have the digital twin show him additional information like the current temperature level of the different coils. Releases and transportation processes are initiated in the digital twin over Drag \& Drop Functions and passed over optimized to the autonomously working cranes and lift trucks by the system. All processes can be checked as an optimized projection into the future. This secures maximum transparency in the logistics planning, Figure 4. 
Figure 4. Dynamic 3D visualization of an Augmented Operation in a digital twin

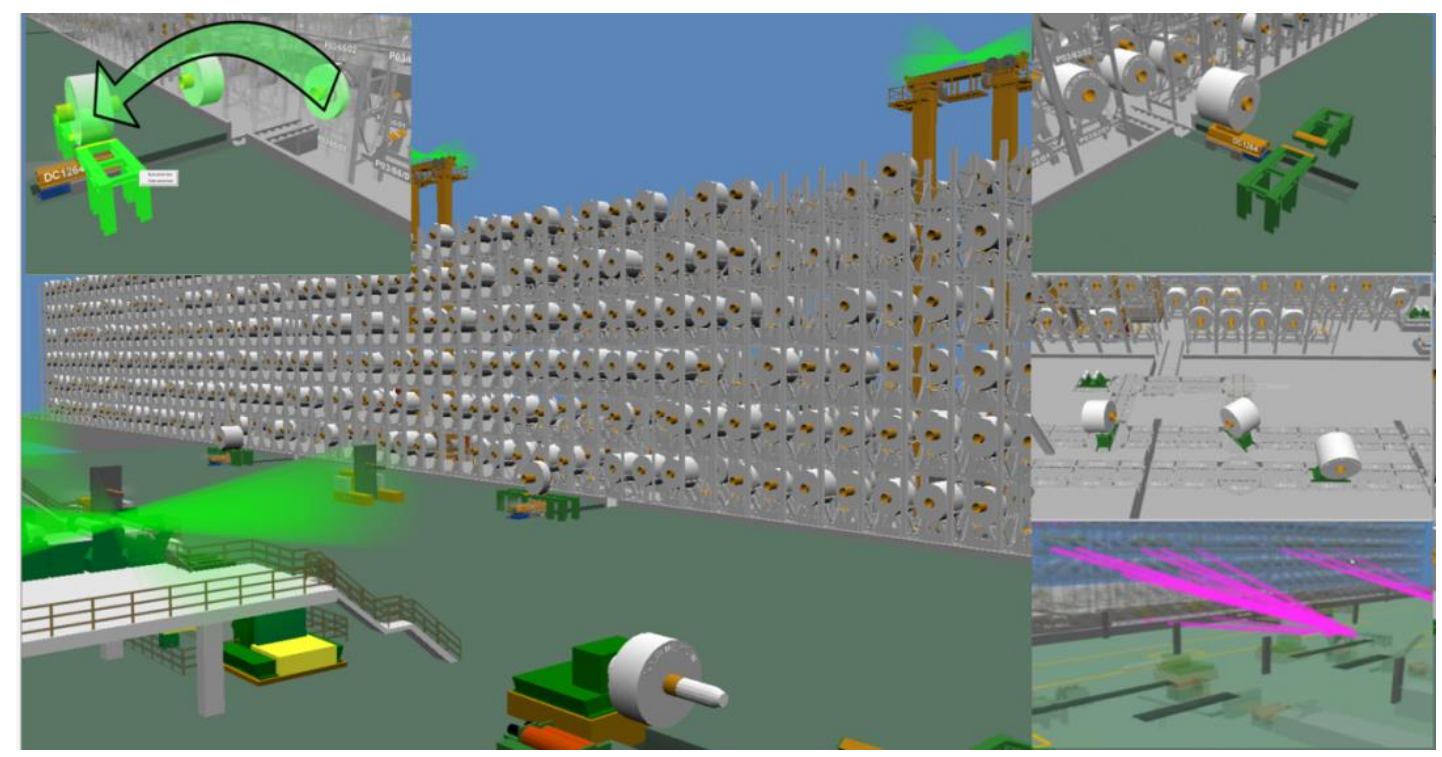

\section{SMS-group Platform Services}

Digital service platforms form the basis for intelligent, digital service competence. The platforms implement the safe, protected digital exchange of information between the companies. One of the first functions SMS-group offers their customers is an eService solution for a faster and more secure identification of spare parts and access to data sheets and maintenance and operating instructions. The electronic spare part catalogue which was introduced during the Tube and Wire 2016 has already been rolled out at a Mini Mill Customer from the USA. The application which is usable at the plant directly and intuitively operable makes it possible to identify the proper spare part or spare part package with few clicks or using a QR-Code. Following this the spare parts procurement process can be initiated either using the internal order process which is established at the customer or directly over the SMSgroup platform, Figure 5. 
Figure 5: Electronic spare part catalogue on the SMS-group platform

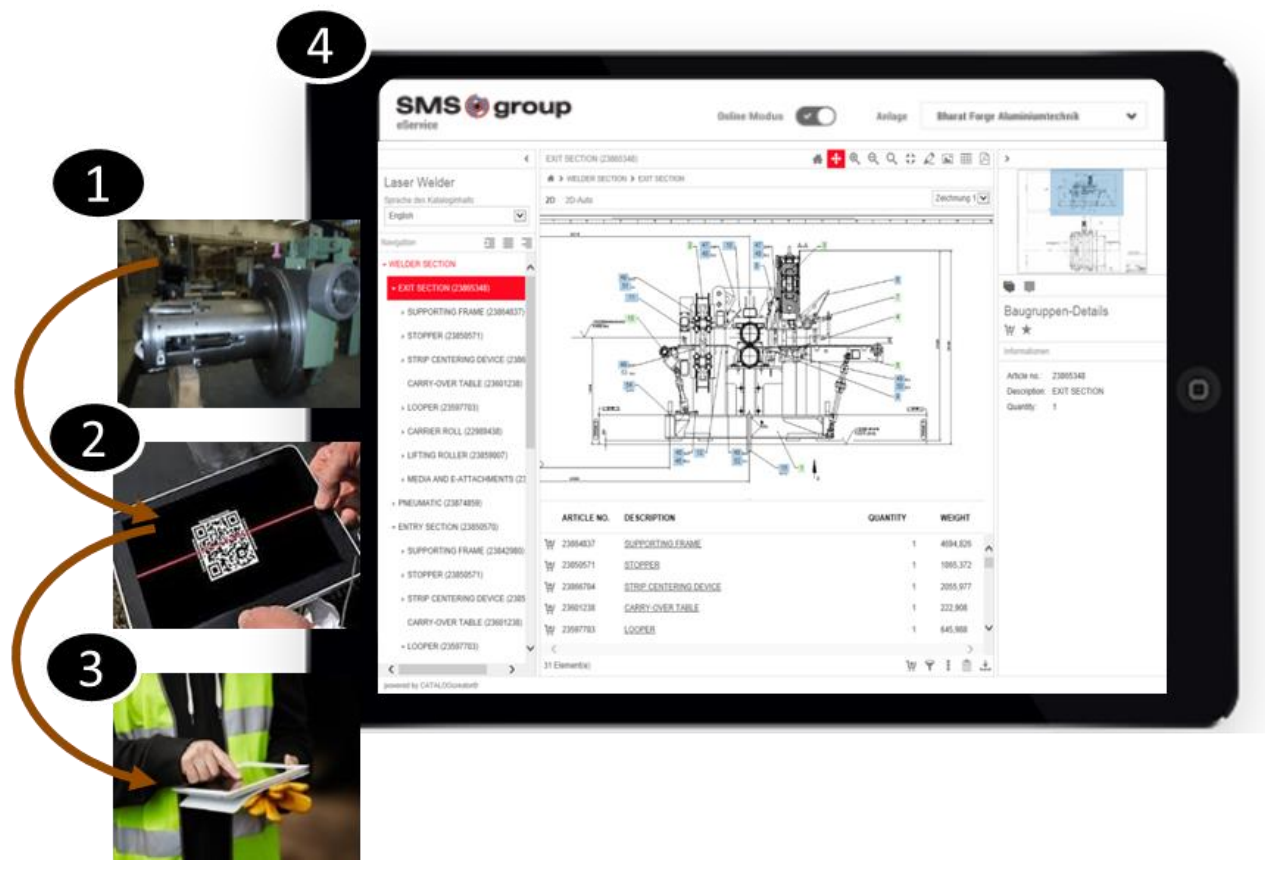

\section{Conclusion}

These were just a few selected examples relating to digitalization. For SMS-group the topic is not just a technological question for the engineers in the company. It concerns everyone at the company and changes existing processes and business models in parts fundamentally. Still SMS-group sees the procedures more as an evolution than as a revolution. It is expected that first changes will happen in the production, maintenance and quality management processes.

The significant enablers that cause these changes are embedded systems, digital service platforms as well as the ability to realize real time networking of data in the plants and to use the performance of Big Data Analytics and Cloud Computing for self-optimizing, autonomic process control. According to estimations by SMS-group digitalization offers new chances to steel producers and plant manufacturers. These lead to a strengthened collaboration, the basis of which digital solutions for both sides can be commercially implemented. 


\section{References:}

[1] Plociennik, Ch.: „Konzeptionelle Ansaetze zur ganzheitlichen Betrachtung von Produktionsanlagen am Beispiel der Walzwerksindustrie“, Shaker Verlag, Aachen, 2014, PhD, RWTH Aachen.

[2] Schauerte, H.: „Ein Stahlwerkssimulator spart Zeit“, VDI Nachrichten 10.11.2006.

[3 Jansen, M.: „Plug \& Work - Ein wichtiger Schritt in Richtung absoluter Fehlerfreiheit", SMS metallurgy Conference 2007, Session 4: Electricsand Automation, Service; SMS-group METEC Booth, Duesseldorf, 12.-16. June 2007. 